\title{
Analyzing The Value Drivers and Path Selection of Grid Corporations From the View of The Long-term Value
}

\author{
Ruobing Shuai ${ }^{1}$ and Yuanbin Jiang ${ }^{2}$ \\ ${ }^{1}$ Guangdong Power Grid Corporation Foshan Power Supply Bureau, Foshan 528000, China \\ ${ }^{2}$ State Grid Chengdu Power Supply Company, Chengdu 610000, China \\ Corresponding author: jybthebest@163.com
}

\begin{abstract}
Based on the business characteristics and EVA, the paper develops an econometric model for the long-term value of grid corporations in China, and analyzes the value drivers and path selection correspondingly. The study shows that, the growing long-term value of grid corporations derives from the creation of future value, and the fundamental factor is an increase in investment. Grid corporations should target at investment management and capital optimization, realizing the goal of long-term value.
\end{abstract}

KeyWords. Economic Value Added, Long-term Value, Value Drivers, Path Selection.

\section{Instruction}

Enterprise Value is a measure of the comprehensive enterprises competitiveness, and obviously continuous value creation reflects enterprise's success. Therefore, achieving the maximum of enterprise value becomes the ultimate objective for the enterprise management.

Like other peers, grid corporations in China(State Grid Corporation of China and China Southern Power Grid Corporation) invests in, constructs and operates power grids, providing safer, cleaner, and more economic and sustainable power supply. Meanwhile, as the state-owned enterprises(SOEs), they are supervised by the State-owned Assets Supervision and Administration Commission of the State Council(SASAC) and evaluated with Economic Value Added(EVA) which targets at the value created in excess of the required return of the shareholders rather than simply the expansion of scale and profit. Hence, it is essential to develop a econometric model for the long-term value of grid corporations, and analyzes the value drivers and path selection correspondingly.

\section{The econometric model for the long-term value and its value drivers}

\subsection{The econometric model}

For the long-term financial performance and value maximization, the management should concentrate on two dominant elements of value creation: revenue growth and accomplishing a return on invested capital (ROIC) beyond the weighted average cost of capital (WACC). Obviously, grid corporations are no exception. Moreover, SASAC has introduced the EVA system to evaluate their performance, which stresses a firm's economic profit, or the value created in excess of the required return of shareholders. The formula is:

$$
E V A=(r-c) \cdot T C
$$


where:

$\mathrm{r}=\mathrm{a}$ return on invested capital

$\mathrm{c}=$ weighted average cost of capital

$\mathrm{TC}=$ the economic capital employed

Based on the existing EVA system and going-concern assumption, we introduce the EVA discount model to measure the long-term value of grid corporations, which is:

$$
E V=A_{0}^{*}+\sum_{t=o}^{\infty} \frac{E V A_{t}}{(1+c)^{t}}
$$

where:

$\mathrm{EV}=$ the long-term enterprise value

$\mathrm{A}_{0}^{*}=$ the opening balance of the net asset value

$\mathrm{c}=$ weighted average cost of capital

$\mathrm{t}=$ the duration of business

Given the certain opening balance of the net asset value, EVA each period in the future and discount rate are two key factors affecting the long-term enterprise value. As for the discount period, in theory, it should be indefinite. However, the longer the discount period is, the lower the accuracy of forecast is. According to the expected make-value management theory, it is reasonable to set the five-years forecast, and the management usually apply such period as the time interval in planning.

The long-term enterprise value is targeting at the discount EVA deriving from both the current and future capital, making up the shortcoming of period indicators fundamentally. It largely decreases the possibility of manipulation and unduly high growth in scale and profit at the cost of sustainable development in the long term.

\subsection{The value drivers}

Based on the econometric model, there are three key components of grid corporations' enterprise value: the opening balance of the net asset value, EVA and WACC in each period. Given the certain the opening balance of the net asset value, we mainly focus on EVA and capital charge in each period.

There are two components of EVA: net operating profit after taxes (NOPAT) and capital charge(WACC x capital).

$$
\begin{aligned}
E V A= & (r-c) \cdot T C=r \cdot T C-c \cdot T C \\
= & N O P A T-c \cdot T C
\end{aligned}
$$

where :

$\mathrm{r}=\mathrm{a}$ return on invested capital

$\mathrm{c}=$ weighted average cost of capital

$\mathrm{TC}=$ the economic capital employed

NOPAT $=$ net operating profit after taxes

Here is the EVA index decomposition of grid corporations:

$$
E V A=N O P A T-c \cdot T C
$$

$\approx$ (Electricity Sales Volume x Average Electricity Sales Price + Other Revenue)- (Electricity Purchase Volume $x$ Average Electricity Purchase Price + Transmission \& Distribution Expenses + Gain/Loss + Taxes $)-($ Current Assets +

$$
\text { Fixed Assets + Other Assets) } x \text { WACC }
$$

Given the characteristics of gird corporations, we can give a snapshot of factors affecting its EVA, as the Figure 1 shows: 


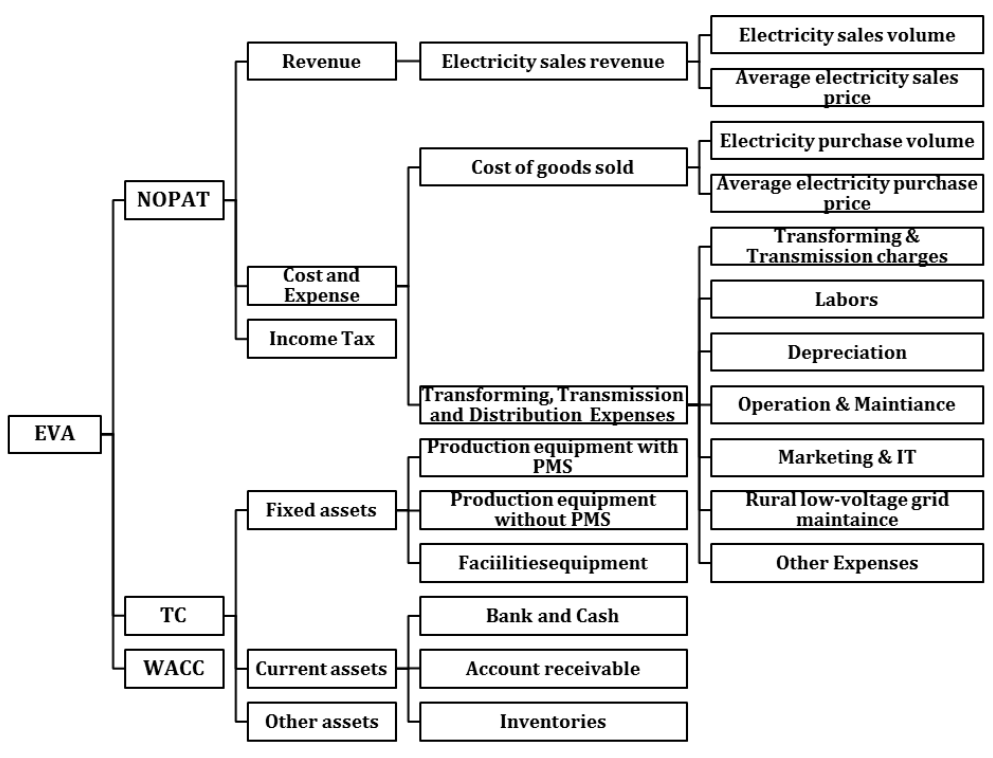

Fig.1. Factors influencing EVA of grid corporations

\subsubsection{Factors influencing net profit after tax (NOPAT)}

Obviously, NOPAT is the key element of grid corporation's EVA, consisting of revenue, cost and income tax. These three mainly reflect the grid corporation's financial appearance during the period of time [1].

(1) Revenue

For grid corporations, the electricity sales revenue is the dominant resource of the revenue, around $90 \%$ of the total. It is determined by electricity sales volume and electricity sales price. Geographically, the electricity sales revenue is divided into provincial electricity sales revenue and interprovincial electricity sales revenue, which are determined by electricity sales price and volumes respectively:

\section{Electricity Sales Revenue $=$ Electricity Sales Volume $x$ Average Electricity Sales Price}

\section{= Provincial Electricity Sales Volume x Average Provincial Electricity Sales Price + Interprovincial Electricity Sales}

\section{Volume x Average Interprovincial Electricity Sales Price}

The average electricity sales price is determined by electricity sales structure (such as large industry usage, commercial usage and resident usage) and consumer-differentiated pricing correspondingly.

(2) Cost and Expense

Cost is necessary for the revenue generating and it is not reasonable to blindly cut the cost and expense in cost of safety and sustainable development, especially for grid corporations balancing the profit-pursing and social-responsibility. The management should target at enhancing the gross margin and thus an increase in NOPAT.

In general, there are two key elements of cost and expense of grid corporations: Cost of goods sold and Transforming, Transmission and Distribution expense.

1) Cost of goods sold

Cost of goods sold is up to $75 \%$ of the total cost and expense of grid corporations, and it is determined by electricity purchase volume and electricity purchase price. Notably, the management must take not only the electricity demand but also the line loss which is the unavoidable loss during the transmission and distribution. The electricity purchase price is determined by electricity purchase structure and supplier-differentiated pricing correspondingly [2]. 
Cost of goods sold= Electricity Purchase Volume $x$ Average Electricity Purchase Price

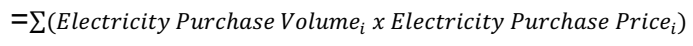

2) Transforming, Transmission and Distribution Expense

For grid corporations, transforming, transmission and distribution expense mainly include transforming \& transmission charge, labors, depreciation, operation \& maintenance, marketing \& IT, rural low-voltage grid maintenance, etc.

Transforming \& transmission charge consists of transmission network use of system (TNUoS) charge and ancillary service charge.

Labors. Like other SOEs, grid corporation's labor costs consist of salary, social insurance, welfare expenses, education and training funds, union funds, housing provident fund (including incremental subsidies), non-monetary benefits, termination benefits and other labor costs.

Depreciation. Due to a tremendous amount of fixed assets, grid corporations have to shoulder the heavy burden of depreciation, a large proportion of cost and expense.

Operation \& Maintenance is necessary to keep on the go for grid corporations, including materials, fixing, etc. Most fixed assets are equipment, which means vast investment, long investment cycle and thus heavy operation \& maintenance cost.

Marketing \& IT. Enterprise resource planning (ERP) system is widely applied in grid corporations, and marketing informatization is one of the essential parts. Such investments help improve energy efficiency, power supply reliability and consumer satisfaction. Rural low-voltage grid maintenance is to guarantee the reliably power supply in rural areas, mainly including rural line loss, remuneration for rural electric management and rural grid operation fees.

Other expenses is the necessary expense for excluding items above [3].

(3) Income Tax

Income tax payable and income tax rate determine the income tax. For grid corporations, the income tax rate was $25 \%$. So, the income tax expense analysis is mainly focused on the income tax payable. There are mainly two aspects to decrease income tax payable and thus reducing the tax burden:

1) Tax planning. The existing enterprise income tax law is more flexible in deduction, expanding the space of tax planning, such as salary restructure, proper choice of accounting policy, transfer pricing, etc.

2) Utilization of Tax preference. Grid corporation can adjust to the change of macropolicy while decision making, especially for investment in technology innovation, environment protection and agriculture support. These fields are strongly encouraged and more likely to utilize corresponding tax preference from the government.

\subsubsection{Factors influencing capital employed (TC)}

Considering grid corporations, there are two aspects of capital employed: create enterprise value through assets employed; increase the use efficiency of assets and thus enterprise value. These two aspects mainly show in occupancy of fixed assets, current assets, and other assets.

(1) Occupancy of fixed assets

Grid corporations are typically asset-intensive enterprise, and fixed assets make up two thirds of total assets. Meanwhile, a vast of fixed assets costs heavy, and their depreciation and obsolescence incur great capital occupancy, which largely weaken value-creating ability.

(2) Occupancy of current assets

Current assets mainly include bank and cash, account receivable and inventory. Holding enough current assets can strong the liquidity, but excessive current assets, especially cash and cash equivalents, are regarded as a waste of 
opportunities and better return, and thus decreasing the enterprise value. Therefore, it is necessary to set proper cash balance.

(3) Occupancy of other assets

Other assets are assets excluding fixed assets and current assets, such as intangible assets, which are essential parts of asset management.

\subsubsection{Factors influencing weighted average cost of capital (WACC)}

WACC is not only the key element of EVA, but also the discount rate in enterprise value calculation, affecting the current operation value directly and the growth value indirectly. It is determined by the capital structure during the financing process. Here is the formula:

$$
W A C C=\frac{D}{D+E} \cdot K_{d}+\frac{E}{D+E} \cdot K_{e} \cdot(1-t)
$$

where:

$\mathrm{D}=$ total debt

$\mathrm{E}=$ total equity

$\mathrm{K}_{\mathrm{d}}=$ cost of debt

$\mathrm{K}_{\mathrm{e}}=$ cost of equity

$\mathrm{t}=$ income tax rate

Notably, grid corporations in China are completely SOEs and their capital result from government capital and some external debt financing. According to the evaluation requirement from SASAC, the WACC is $4.1 \%$ for both equity capital and debt capital, stressing the safety of capital structure rather than economical efficiency [4].

\section{The path selection of long-term value improvement}

\subsection{Investment management based on value development}

Due to the value composition of grid corporation, its enterprise value consists of current operation value and growth value in the future, and the latter decides the long-term value. For gird corporation, the emphasis is the investment, and cherry-picking the projects with better return. The increases in return of incremental capital will largely enhance EVA in the future.

\subsubsection{The scope of investment}

(1) Fixed-asset investment includes medium and large construction, expansion, technical innovation, informatization, and other fixed-asset investments.

(2) Equity investment includes establish new companies, mergers and acquisitions (M\&A), and other equity investments.

Achieving better return is the topic never out of topic in investment management. Under EVA, principles below must be followed: firstly, the investment project must make a contribution towards EVA positively during the life cycle, and the corresponding EVA target and rejection standard must be re-established in case of oversize scale and low efficiency; secondly, such project must conform to the company goals, highlight the main operation, and keep ahead in competitive business; lastly, such project must secure the compliance of the law and policy [5].

\subsubsection{Investment analysis}


While investment decision-making, an investment is considered valuable when it generates more NOPAT than cost of capital. For grid corporations, investment driving consists of investment in various business segments and the expansion in certain area, and the basis of decision-making is positive EVA. It means the investment can bring excess return, and thus creating value. Based on growth-oriented investment behaviors, both EVA return rate, which is return on invested capital (ROIC) less WACC, and net investment growth rate should be considered. Here is the $2 \mathrm{~d}$ scatter plot of these two:

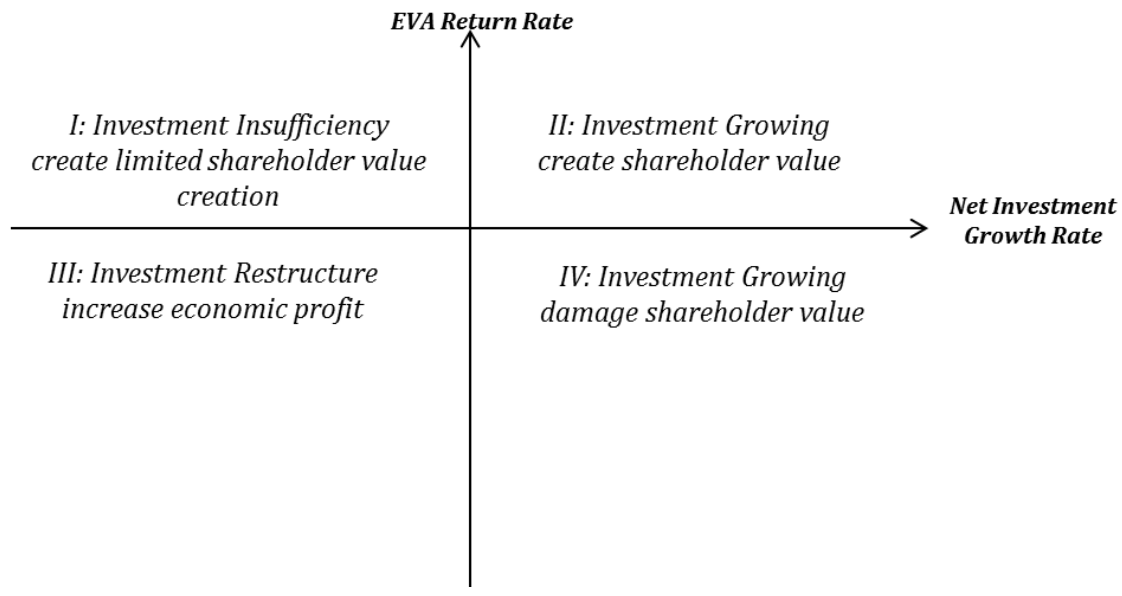

Fig.2. Investment Behavior Analysis

\subsubsection{Capital optimization based on EVA}

Introducing EVA could make the management keep eyes on capital optimization because it stresses the cost of capital employed. The management could adjust the capital structure through more flexible financing method and tools.

Based the analysis of value drivers and its resources, capital optimization should be considered in reducing capital occupancy and decreasing the cost of capital:

(1) Accelerate the capital flows

From the view of the whole company, as a result of different life cycle of each business segment, the volume of capital needed vary according to the growth rate of market and market share. The capital can be better utilized through adjusting the capital distribution in each business segment. During the redistribution, the grid corporation can shift the capital into the high value-added business from the low value-added businesses, improving the profitability of whole company. Such flow path can be clearly shown with BCG Matrix [6].

1) Question Marks mean businesses with low market share in a high growth market. It is regarded as a starting pointing with great potential but uncertainty as well. The best path is becoming the stars and finally cash cow after fast growing. If fail, it will enter the quadrant of dogs.

2) Stars mean business with high market share in a high growth market. It is the "superstar" because of both continuous growing and great profitability. As the strategic segment of enterprise objective, it makes large contribution to the whole enterprise value for both the current and future, and needs to increase the investment for expanding business and keeping competition advantage.

3) Cash cows mean businesses with high market share in a low growth market. It is regarded as mature business with high profit margin but less potential. It holds vast of surplus capital and does not need large-scale market. Therefore, it is the shield of other businesses, especially the stars. 
4) Dogs mean businesses with low market share in a low growth market. It is considered to be a declining period with low margin or even deficit, and can hardly create value for the enterprise.

Before introducing EVA, grid corporations make efforts to launch projects as many as possible due to adverse selection. It causes enormous waste of resource and capital idle. In terms of EVA, any capital idle incurs cost, and blind investment will largely weaken the financial performance. In particular, applied the BCG Matrix into the business of grid corporations, the traditional grid network business, especially large-industry customer market, is the typical cash cows with stable return but slow growing (or even declining). On one hand, the stable return results from the price scissors between buying and selling, determined by the government. On the other hand, the market is growing slowly, or even declining, due to challenge from overproduction and corresponding supply-side reform. Therefore, to enhance EVA, investing smart grid has become the inevitable tendency. Smart grid is a fully automatic power transmission network with a variety of operational and energy measures, controlling each connection and guaranteeing the information and power flow in both direction. It mainly consists of user interaction, intelligent device, internet of things, big data, self-prediction \& self-healing \& self-adjustment, which can largely strong the EVA and power supply reliability in the future. Currently, such area is still the Question Marks, which means great potential but less profit and market share, and cost heavily, even reduce the EVA. But, based on the long-term value, smart grid is a chance to win the future and can be continuously "milked" by our cash cows.

(2) Decrease the capital cost rate

Decreasing the capital cost is another effective way to optimize the capital. Given the certain capital employed, lower capital cost rate can decrease the total capital cost and thus enhancing EVA. Emphasizing the existence of cost of equity capital, EVA makes the management consider the balance between the cost of equity capital and the cost of debt equity (which is relatively tax-saving), and then make the right decision in financing. It is worth thinking about whether the financing will increase the EVA, to avoid blindly financing expansion and capital idle from it.

\section{Conclusion}

Based on the business characteristics and EVA, the paper develops an econometric model for the long-term value of grid corporations in China, and analyzes the value drivers and path selection correspondingly. The study concludes that:

\subsection{The value drivers of grid corporations}

We have analyzed the value drivers of grid corporations in the future growth value and current operation value. Given the certain current operation value, we conclude that the root cause of future growth value is an increase in investment. Some factors happened currently will influence the value in the future. For example, asset overhaul not only affect current operating cost, but also affect the cost of overhaul in the future. Therefore, the decision-making of these factors should reflect the value maximization in the whole life cycle.

\subsection{The path selection of long-term value improvement}

The analysis of value drivers helps the management clarify the mechanism of value creation, rationalize the distribution of resources and eventually enhance the enterprise value. Based on the value drivers, the study has established the path of achieving the long-term value enhancement: investment management based on value development and capital optimization based on EVA. 


\section{References}

1. Chen Zhibin, 2006. Analyzing Model of Value-Creation Factors from the View of Free Cash Flow Management [J]. Accounting Research 4, 58-62

2. Zhao Zhenquan, Geng Yuxin, 2005. The Application of Value Added Method to Corporate Evaluation [J]. Contemporary Economic Research 4, 43-47

3. Pan fei, Wen Donghua, 2006. Recent empirical study on managerial accounting and future research direction of China: based on value-based management [J]. Accounting Research 2, 81-86

4. Ittner, C., Larcker, D., 2001. Assessing empirical research in managerial value based management perspective [J]. Journal of Accounting and Economics 32, 349-410

5. Lloyd, W., DAVIS, L., 2007. Building Long-Term Value- Objective financial analysis focuses clients on business revenue growth [J]. Journal of Accountancy 204.5, 56-62

6. Federal Energy Regulatory Commission Assessment of Demand Response \& Advanced Metering. United States Federal Energy Regulatory Commission. United States Federal Energy Regulatory Commission. 